\title{
EFFECTS OF PRECIPITATION ON RECRYSTALLIZATION TEXTURES IN Al-Ge ALLOY
}

\author{
Y. KANENO, H. INOUE AND N. INAKAZU \\ Department of Metallurgical Engineering, \\ University of Osaka Prefecture, \\ 4-804, Mozu-Umemachi, Sakai, Osaka, 591, Japan.
}

\begin{abstract}
The recrystallization textures of $\mathrm{Al}-4.0 \mathrm{wt} \% \mathrm{Ge}$ alloys with the different states of precipitation before cold rolling were determined by means of orientation distribution functions (ODFs). Additionally, measurements of the hardness and the electrical resistivity and optical microscopic observation were carried out to investigate the process of recrystallization and precipitation, and effects of two kinds of precipitates were revealed. Recrystallization textures were strongly dependent on annealing temperature. At higher temperatures, discontinuous recrystallization occurred, while continuous recrystallization predominated at lower temperatures. This was due to the precipitation during annealing. On the other hand, it was found that precipitates which existed before cold rolling randomized recrystallization textures.
\end{abstract}

\section{INTRODUCTION}

It is known that the recrystallization behavior of aluminium alloy is affected by second phase particles. If the precipitation takes place during the recrystallization, small precipitates impede boundary migration so that continuous recrystallization occurs. On the other hand, the influence of large particles on deformation and recrystallization texture has been investigated $^{1)-3}$. In this study the recrystallization textures of $\mathrm{Al}-\mathrm{Ge}$ alloys in which precipitation states are different before cold rolling were measured as a function of annealing temperature. The effects of two kinds of precipitation processes (before deformation and during annealing) on texture were examined. 


\section{EXPERIMENTAL PROCEDURE}

Aluminium and germanium form a simple eutectic system and the maximum splubility of $\mathrm{Ge}$ in $\mathrm{Al}$ is $5.2 \mathrm{wt} \%$ at a eutectic temperature of $693 \mathrm{~K}^{4}$. In this work, $\mathrm{Al}-4.0 \mathrm{wt} \% \mathrm{Ge}$ alloy was used. The material was prepared from $99.99 \%$ purity aluminium and $99.99 \%$ purity germanium by melting and casting into a chill mold. After hot extruded as a sheet shape, the alloy was solution treated at $693 \mathrm{~K}$ for $86.4 \mathrm{ks}(24 \mathrm{hrs})$ and subsequently quenched in water or cooled in a furnace for the purpose of changing the precipitation state. The specimens will be called ST for the water-quenched sample and PT for the furnace-cooled one, respectively. They were cold rolled to $90 \%$ reduction in thickness, and then isothermally annealed at various temperatures in a salt bath or in the oil bath. The recrystallization and the precipitation process were investigated by means of the measurements of hardness and electrical resistivity and the optical microscopic observation. The precipitates were identified by using the X-ray diffraction method. Textures were measured in the central layer of the sheet by using $\mathrm{CuK} \alpha$ radiation. The orientation distribution functions (ODFs) were calculated from the data of three complete pole figures $(\{111\},\{200\}$ and $\{220\})$ by the series expansion method.

\section{RESULTS AND DISCUSSION}

The textures and the optical micrographs of the starting materials are shown in Figure 1. The initial textures of both the quenched (ST) and the slowly-cooled (PT) sample were quite sharp and similar to each other. They consisted of the cube component with spread around ED (extrusion direction). Both the samples showed equiaxed grains and their sizes were almost equal. However, the large precipitates were observed in the PT sample and the peak of Ge appeared in the X-ray diffraction profile only for the PT sample. These results indicated that both samples were almost in the same conditions before cold rolling except for the precipitation state.

Figure 2 shows the changes in hardness with isothermal annealing. There are few differences in the softening process between the ST and the PT sample for any annealing temperature. It is found that the hardness is almost unchanged or changed only slightly for the first stage and then decreases gradually at $473 \mathrm{~K}$, and that, on the contrary, the softening is completed in only a few seconds at $673 \mathrm{~K}$. From the results of the hardness measurement, the necessary times for recrystallization at each annealing temperatures, that is, the times which the samples were completely softened and come to $\mathrm{Hv} \simeq 40$, were determined.

The results of texture measurements are shown in Figure 3. 
In the deformed state, textures of both samples are quite similar to each other, and no clear differences are noticed in spite of the difference in the precipitation state before cold rolling. Although the rolling textures basically show a pure metal-type (copper-type), they are somewhat shifted toward an alloy-type (brass-type). The maximum of orientation density along the orientation tube ( the so called " $\beta$-fiber") are plotted vs. the angle $\varphi_{2}$ in Figure 4. It is found that the skeleton lines are more similar to those of an alloy-type rather than a pure-type ${ }^{5)}$.

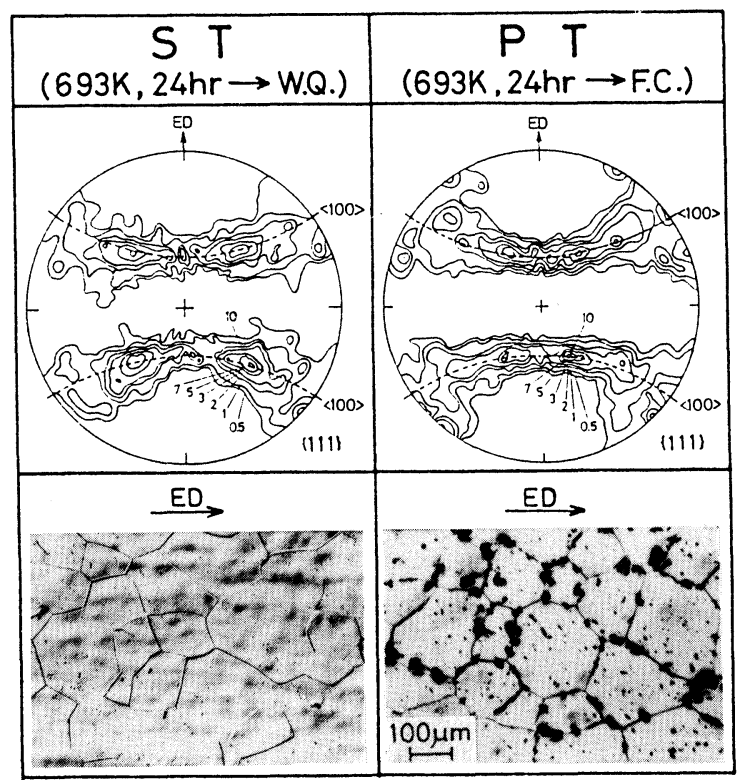

Figure $1\{111\}$ pole figures and optical micrographs of the starting materials.

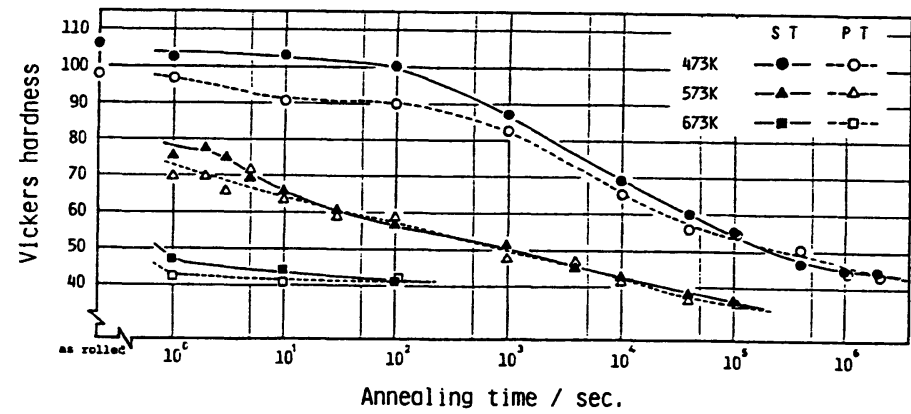

Figure 2 The changes in hardness with isothermal annealing. 


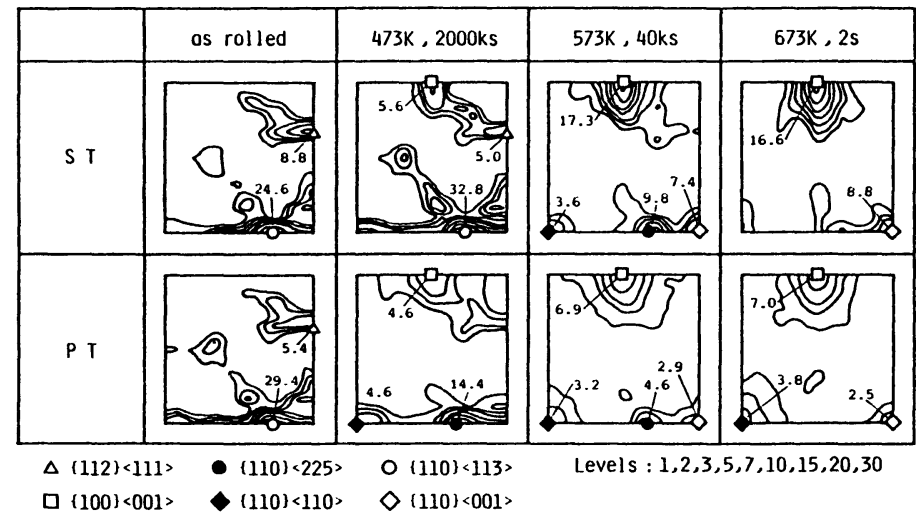

Figure $3 \varphi_{2}=45$ sections of ODFs for the samples cold rolled and annealed.

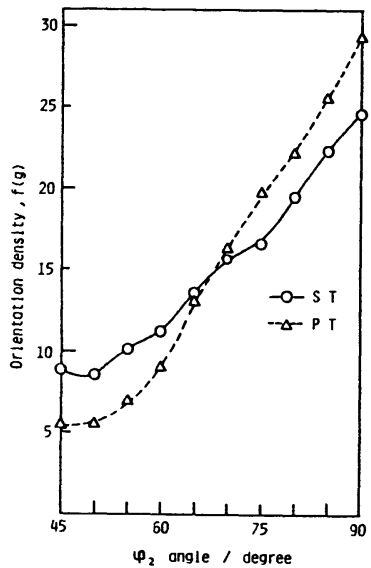

Figure 4 Skeleton lines of rolled samples.

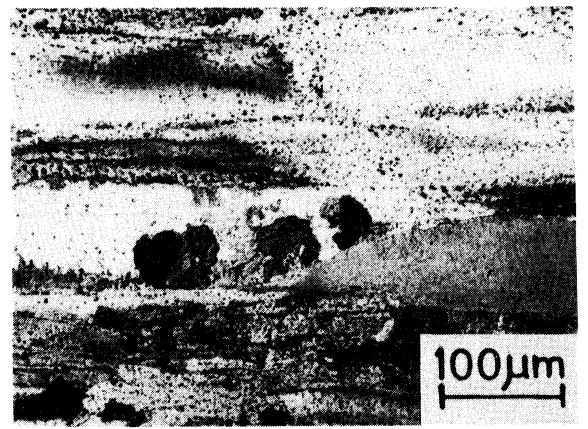

Figure 5 Optical micrograph of the ST sample annealed at $473 \mathrm{~K}$ for $2000 \mathrm{ks}$.

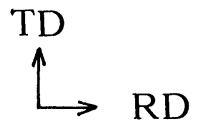

The recrystallization textures are strongly dependent on the annealing temperature (Figure 3). For the ST sample, a cube orientation $\{100\}<001>$ is formed at $673 \mathrm{~K}$ as formed in pure aluminium. In addition, the orientation $\{110\}<001\rangle$ and the orientation $\{110\}<110\rangle$ can be also found. It is known that these orientations related to the deformed matrix by $40^{\circ}-\langle 111\rangle$ rotational relationship. At $573 \mathrm{~K}$, while these orientations are recognized, the orientation $\{110\}<225\rangle$, which is close to $\{110\}<112\rangle$, is present in small amounts. At $473 \mathrm{~K}$, some considerable differences in the recrystallization textures are found. Although the cube component is observed, the recrystallization 
texture consists mainly of the components of the rolling texture.

The results of optical microscopic observation correspond to the change in recrystallization texture. At $473 \mathrm{~K}$, a few equiaxed grains can be seen, but the major part of the specimen is occupied by the elongated grains which are similar to those of deformed sample (Figure 5). On the contrary, only equiaxed grains are observed at $673 \mathrm{~K}$. At $573 \mathrm{~K}$, both the elongated and the equiaxed grains are present in the specimen. These results suggest that continuous recrystallization is dominant at a low temperature and discontinuous recrystallization occurs at a high temperature.

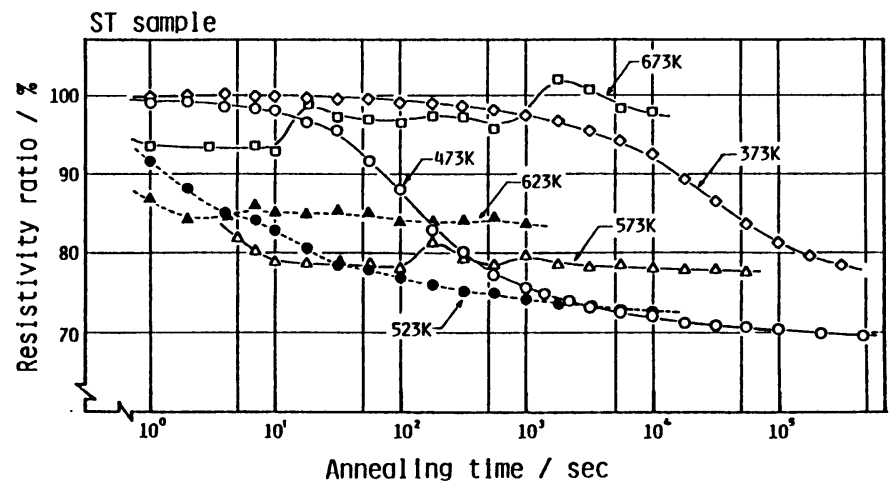

Figure 6 The changes in electrical resistivity of the ST sample with isothermal annealing.

Figure 6 exhibits the changes in electrical resistivity during isothermal annealing for the ST sample. Similar results are obtained for the PT sample. The difference between the ST and the PT sample is that the amount of the decrease is less than the ST sample. The total amount of decrease in electrical resistivity is less at higher temperatures. This is ascribed to the enlargement of the solubility limit of $\mathrm{Ge}$ in $\mathrm{Al}$. Therefore, at higher temperatures precipitation does not occur, or only slightly even if it does. At lower temperatures, electrical resistivity decreases significantly and this indicates that precipitation takes place. By comparing with the variation of hardness (Figure 1), it can be thought that because no precipitation participates in recrystallization at $673 \mathrm{~K}$, a cube texture accompanied by additional components which are related to the rotational relationship is formed, and also that because precipitation occurs during recovery or early in the recrystallization, deformation texture is retained strongly at $273 \mathrm{~K}$ on account of the pinning effect of fine precipitates.

Similar results can be found for the PT sample. But, compared with the ST sample, the recrystallization textures of the PT 
sample are weaker than those of the ST sample irrespective of annealing temperature. This is thought to be attributed to the following fact; if the large particles exist before the deformation, inhomgeneously deformed regions (deformation zone) are formed around the particles by the deformation. In such regions, the nuclei whose orientations are random are generated ${ }^{69}$ and therefore the recrystallization textures are randomized and weakened. However, the main components of recrystallization textures are basically the same as those of the ST sample. Therefore, the effects of two kinds of precipitation processes, which are due to fine precipitates during annealing and to coarse ones which exist before cold rolling, are operated in the PT sample.

\section{CONCLUSION}

Recrystallization textures of cold rolled $\mathrm{Al}-4.0 \mathrm{wt} \% \mathrm{Ge}$ alloy are strongly dependent on annealing temperature irrespective of the precipitation state before cold rolling. Discontinuous recrystallization occurs and a cube texture is formed at higher temperatures where precipitation does not occur, while continuous recrystallization takes place because precipitation occurs during annealing and the rolling texture is strongly retained at lower temperatures. Precipitates which exist before cold rolling randomize the recrystallization textures to a considerable extent whereas they do not seriously affect the rolling texture.

\section{ACKNOWLEDGMENT}

The authors would like to thank A. Yamashita (graduate student, University of Osaka Prefecture) for his help in contributing experimental results.

\section{REFERENCES}

1) H.W. Erbsloh, P. Bronder and K. Lücke, Proc. 7th Int. Conf. on Textures, 221(1984)

2) D.J. Jensen, N. Hansen and F.J. Humphreys, Acta metall., 33, 2155(1985)

3) O. Engler, J. Hirsch and K. Lücke, Acta metall., 37, 2743 (1989)

4) T.B. Massalski, Binary Alloy Phase Diagrams (ASM, 1986), 1, p. 116

5) J. Hirsch and K. Lücke, Acta metall., 36, 2863(1988)

6) P. Herbst and J. Huber, Proc. 5th Int. Conf. on Textures, 1, 453(1978) 